\title{
GEOMAGNETIC METHOD FOR AUTOMATIC DIAGNOSTICS OF AURORAL OVAL BOUNDARIES IN TWO HEMISPHERES OF EARTH
}

\section{Yu.V. Penskikh}

Institute of Solar-Terrestrial Physics SB RAS, Irkutsk, Russia,penskikh@iszf.irk.ru

\section{S.B. Lunyushkin}

Institute of Solar-Terrestrial Physics SB RAS, Irkutsk, Russia, lunyushkin@iszf.irk.ru

\author{
V.E. Kapustin \\ Institute of Solar-Terrestrial Physics SB RAS, \\ Irkutsk, Russia, kapustin@iszf.irk.ru
}

\begin{abstract}
The ground-based automatic method for determining auroral oval (AO) boundaries developed by the authors [Lunyushkin, Penskikh, 2019] has been modified and expanded to the Southern Hemisphere. Input data of the method contains large-scale distributions of the equivalent current function and field-aligned current density calculated in the polar ionospheres of two hemispheres in a uniform ionospheric conductance approximation based on the magnetogram inversion technique and the geomagnetic database of the world network of stations of the SuperMAG project. The software implementation of the method processes large volumes of time series of input data and produces coordinates of the main boundaries of $\mathrm{AO}$ in both hemispheres: the boundaries of the ionospheric convection reversal, the $\mathrm{AO}$ polar and equatorial boundaries, the lines of maximum density of field-aligned currents and auroral electrojets. The automatic method reduces the processing time for a given amount of data by 2-3 orders of magnitude (up to minutes and hours) compared
\end{abstract}

to the manual method, which requires weeks and months of laborious operator work on the same task, while both methods are comparable in accuracy. The automatic geomagnetic method has been tested for diagnostics of AO boundaries during the isolated substorm of August 27, 2001, for which the expected synchronous dynamics of polar caps in two hemispheres has been confirmed. We also show the AO boundaries identified are in qualitative agreement with simultaneous AO images from the IMAGE satellite, as well as with the results of the OVATION and APM models; the boundary of ionospheric convection reversal, determined by the geomagnetic method in two hemispheres, is consistent with the maps of the electric potential of the ionosphere according to the SuperDARN-RG96 model.

Keywords: equivalent current function, convection reversal boundary, magnetogram inversion technique, field-aligned currents, auroral oval boundaries.

\section{INTRODUCTION}

The auroral oval is an essential structural element of the high-latitude ionosphere, a region of observable discrete and diffuse auroras generated by energetic electron and proton fluxes continuously precipitating from the magnetosphere and increasing during magnetospheric substorms and storms many times. The high-latitude boundary of the auroral oval (AO) corresponds to the boundary of the polar cap (PC, the boundary of closed and open geomagnetic field lines); and the low-latitude AO boundary, to the plasmapause and the inner edge of the plasma sheet. According to our current understanding of physics and topology of Earth's magnetosphere, nightside AO and PC regions in two hemispheres are conjugate ionospheric projections of the plasma sheet, which contains dense plasma in closed field lines, and two very extended magnetotail lobes with rarefied plasma and field lines open (or highly stretched) to the solar wind [Akasofu, 1977; Feldstein, Galperin, 1985; Heikkila, 2011]. The largescale structure (shapes, boundaries, and dimensions) of the tail lobes and plasma sheet is determined by quasistationary physical processes of mass, momentum, and energy transfer from the solar wind to the magnetosphere, as well as by explosive processes of accumulated tail magnetic energy release during substorms. Studying the space-time dynamics of AO boundaries in conjugate ion- ospheres, shape and position of PC, and open magnetic flux through them under quiet and disturbed geomagnetic conditions is a long-standing, but still topical scientific problem of physics of the magnetosphere and magnetospheric substorms [Akasofu, 1977, 2013; Shukhtina et al., 2016], which we address in this paper.

Planetary morphology and dynamics of auroras are investigated using a variety of ground (photography and filming, photometry and spectroscopy, radars) and satellite (particle detectors, photography, and photometry) facilities and methods [Jones, 1974]. Half a century ago, analysis of a large amount of aurora photographs taken by all-sky cameras at the global network of groundbased observatories promoted the development of the AO concept [Feldstein, 1964; Khorosheva, 1967; Akasofu, 1977] and the first statistical models of AO for different geomagnetic activity levels [Feldstein et al., 1968]. Current studies of the polar ionosphere make full use of three satellite methods of observing $\mathrm{AO}$ and identifying its boundaries. The first method relies on insitu (along a satellite path) measurements of parameters of the energy spectrum of precipitating magnetospheric electrons and protons and determines AO boundaries from steep gradients of these parameters. Passes of a satellite over a particular geographical point are separated by an interval of 100 min, therefore this local method cannot give an instantaneous spatial structure of AO 
boundaries even along one satellite path. Nonetheless, a large amount of long-term satellite data from the wellknown DMSP project facilitated the development of informative statistical models of AO boundaries such as OVATION [Newell et al., 2014] and APM [Vorobjev et al., 2013]. The second method provides a global diagnostics of AO with a step of $\sim 2$ min based on its UV photography by Wideband Imaging Camera (WIC) on board satellites with polar orbits (IMAGE \& Polar Project) [Boakes et al., 2008; Longden et al., 2010]. Shortcomings in this method are often incomplete coverage of AO and PC by the camera as well as high exposure of dayside AO to solar ultraviolet [Milan et al., 2009]. Moreover, to ensure continuous and simultaneous global diagnostics of AO in both hemispheres requires stable operation of at least two expensive polar satellites. Over recent years, the third satellite method of diagnosing AO boundaries from 2D maps of field-aligned current (FAC) distributions has been rapidly developed under the large project AMPERE. In this project, a constellation of several tens of satellites provides a continuous calculation of such FAC maps in two hemispheres at a temporal resolution of $\sim 10 \mathrm{~min}$ [Coxon et al., 2018; Burrell et al., 2020]. Obviously, the development of new methods of AO diagnostics at a higher spatial and temporal resolution is necessary as an alternative and/or supplement to the existing tools and methods for a more complete understanding of physical processes in the solar wind — magnetosphere — ionosphere system and for solving the topical scientific problem of magnetospheric substorms.

In this paper, we continue elaborating the new ground-based geomagnetic method for automatic diagnostics of AO boundaries from output data, obtained with the magnetogram inversion technique (MIT). The main principles of this method have been formulated in [Kondratyev et al., 2017; Lunyushkin, Penskikh, 2019]. The main purposes and objectives of this study are to develop the geomagnetic method for simultaneous diagnostics of $\mathrm{AO}$ boundaries in two hemispheres; to test the accuracy of the method as per manual/automatic; to compare the AO boundaries determined by the geomagnetic method with direct AO observations from the IMAGE satellite and results of the SuperDARN, OVATION, APM models.

\section{ALGORITHM OF THE GEOMAGNETIC METHOD}

The ground-based geomagnetic method for automatic diagnostics of AO boundaries in two hemispheres is based on MIT, developed at ISTP SB RAS [Bazarzhapov et al., 1979; Mishin, 1990; Shirapov, Mishin, 2009]. MIT calculates two-dimensional distributions of equivalent currents, electric potential, horizontal and field-aligned currents, and other electrodynamic parameters of the high-latitude ionosphere from 1-min geomagnetic measurements at the worldwide network of ground stations. In recent years, the MIT software package has been significantly modernized and completely adapted to the research work on the basis of a unified database of digital geomagnetic data, created in the ambitious project SuperMAG [Gjerloev, 2012]. This database containing an extensive annually updated archive is available at [https://supermag.jhuapl.edu].

Physical principles, theory, and basic algorithm of the geomagnetic method have been detailed in our paper [Lunyushkin, Penskikh, 2019]. Below, we briefly describe only the main of them.

The method employs large-scale spatial distributions of the equivalent current function $J(\theta, \lambda)$ and FAC density $i_{\|}(\theta, \lambda)$, calculated at the first stage of MIT in the approximation of radial geomagnetic field and uniform ionospheric conductance:

$$
\begin{aligned}
& J=\mp \Sigma_{\mathrm{H}} U+J_{0}, \\
& i_{\|}=-\frac{\Sigma_{\mathrm{P}}}{\Sigma_{\mathrm{H}}} \Delta J,
\end{aligned}
$$

where in the first term of (1) the upper sign (minus) represents the Northern Hemisphere; and the lower sign (plus), the Southern Hemisphere; $J_{0}$ is the calibration constant; $U=U(\theta, \lambda)$ is the ionospheric electric potential distribution; $\theta$ is the geomagnetic colatitude; $\lambda$ is the local geomagnetic time; $\Delta$ is the Laplace operator; $\Sigma_{\mathrm{P}}$, $\Sigma_{\mathrm{H}}$ are the height-integrated Pedersen and Hall conductance given by constants $\Sigma_{\mathrm{H}}=10 \mathrm{~S}$ and $\Sigma_{\mathrm{P}} / \Sigma_{\mathrm{H}}=1$; Formula (2) is the same for both hemispheres.

From (1) follows $\Delta J=\mp \Sigma_{H} \Delta U$, whose substitution in (2) establishes a connection between the FAC density $i_{\|}$ and the electrostatic potential $U$ :

$$
i_{\|}= \pm \Sigma_{\mathrm{P}} \Delta U \text {. }
$$

Substituting the Poisson equation $\Delta U=-\rho /\left(\varepsilon \varepsilon_{0}\right)$ in (3) shows a relationship between $i_{\|}$and electric charges transferring FAC and $U$ from magnetospheric EMF generators to the ionosphere.

Formula (1) allows us to utilize $J$ as $U$, and the gradient of $J$ as the electric field $\mathbf{E}$ producing the ionospheric convection:

$$
\nabla J=\mp \Sigma_{\mathrm{H}} \nabla U= \pm \Sigma_{\mathrm{H}} \mathbf{E} .
$$

On the basis of elementary physical formulas (1)(4), we have developed an algorithm for diagnosing magnetosphere-ionosphere convection reversal boundary $(\mathrm{RB})$ - the most important physical parameter that controls the mass and energy transfer from the solar wind to the magnetosphere through the mantle of open tail lobes and the low-latitude boundary layer. RB necessarily passes through two main focuses of the current function $J$, which match dawn and dusk extrema in the $U$ distribution, and also coincides with the maximum density line of region 1 FACs transmitting the electric potential $U$ from the main generator solar wind magnetosphere to the ionosphere. In our method, we have implemented two approaches to identifying RB: from the equivalent current function $J$, where RB passes through the points with minima of $\nabla J$; from the distribution of FAC density - in this case RB is drawn along the line of region 1 FAC density maxima. The two ap- 
proaches can be used both simultaneously and independently, for example, when determining RB from models of electric potential (SuperDARN, etc.) and/or FAC (AMPERE, etc.).

Figure 1, using one of the moments of the August 27, 2001 substorm as an example, illustrates the above approaches to determining RB on maps of current function (left) and FAC (right). Here and in all similar figures, red isolines indicate a positive value of the function; blue, a negative one. In [Lunyushkin, Penskikh, 2019], we have shown theoretically that the two approaches are interrelated and should yield the same results (with an accuracy defined by the computation grid spacing in latitude), which has been confirmed then and during the follow-up study. The meaning of other AO boundaries (R0, R1, R2, RH), shown in Figure 1, is explained in the next section.

The magnetic conjugation of $\mathrm{AO}$ in two hemispheres with the plasma sheet, noted in Introduction, is also provided by the electrodynamic magnetosphere ionosphere coupling through large-scale IijimaPotemra region 1 and 2 FACs [Iijima, Potemra, 1978] flowing along geomagnetic field tubes of conjugate regions. The spatial correspondence between regions 1, 2 of FAC and AO has been confirmed by many studies [Coley, 1983; Fujii et a.l, 1990; Gary et al., 1998; Korth et al., 2014; Carter et al., 2016; Xiong et al., 2020]. In terms of this conjugation, a visualmanual method of determining AO boundaries from maps of large-scale FAC distributions has long since been put into practice of MIT [Mishin et al., 1986, 1992]. The AO polar boundary (or PC boundary designated as R0) is determined from the high-latitude boundary of FAC region 1 (see Figure 1, right); and its equatorial boundary (R2), from the low-latitude boundary of FAC region 2 . We also find the boundary between FAC regions 1 and 2 (R1) that represents latitudinal maxima of intensities of westward and eastward auroral electrojets, further determine the line of region 2 FAC density maxima $(\mathrm{RH})$. It is necessary to clarify here that in the designations we have adopted

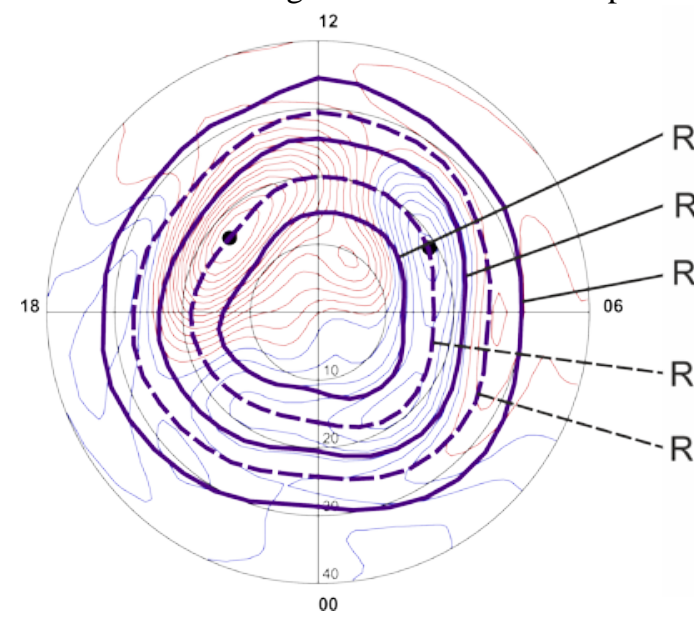

Figure 1. Equivalent current function (left) and FAC density (right) with uniform conductance in the Northern Hemisphere for 03:55 UT on August 27, 2001: R0 is the polar cap boundary; RB is the convection reversal boundary (the line of maximum density of region 1 FAC); R1 is the boundary between FAC regions 1 and 2; RH is the line of maximum density of region 2 FAC; $\mathrm{R} 2$ is the equatorial boundary of AO; heavy dots are the principal focuses for the AO boundaries (R0, RB, R1, RH, and R2) the letter $\mathrm{R}$ (Radius) means the radius vector measured from the pole in colatitude degrees of the polar coordinate system used in MIT. The radii R0, R1, and R2 representing southern boundaries of region 0,1 , and 2 FACs should not be confused with similar designations $\mathrm{R} 0, \mathrm{R} 1$, and R2 frequently used in the literature for three Iijima-Potemra FAC regions.

The long-term and vital methodical task of the MIT software package is to work out an automatic method of determining AO boundaries as alternative to the timeconsuming visual-manual method. We have largely accomplished this task [Lunyushkin, Penskikh, 2019]. In this paper, we extend the ground-based geomagnetic method of diagnosing $\mathrm{AO}$ boundaries, in particular to the Southern Hemisphere. Below, we describe algorithms of the geomagnetic method with some refinements, extensions, and modifications.

\section{Search for principal focuses}

The boundary R1 separates areas of downward and upward FACs 1 and 2 inside AO; and the boundary R0, region 1 and 0 FACs in PC (Figure 1). Obviously, the larger the amplitude of FAC density variations before and after the FAC boundary, the sharper this boundary between them and the easier its determination. It is also clear that the maximum amplitude of the variations is on the meridian with minimum/maximum FAC density. In the vicinity of two main focuses of region 1 FAC, defined too. In the vicinity of two main focuses of the current function $J$, the ionospheric convection reversal boundary RB is usually clearly-cut. These minima and maxima of $J$ (as an analog of the electric potential) are located, according to the theory and observations, near the dawn-dusk meridian [Heppner, 1972; Lu et al., 1989].

At the beginning of this section, we have emphasized that the ionospheric convection reversal boundary $\mathrm{RB}$ necessarily passes both through the dawn and dusk boundaries between FAC regions are generally well-

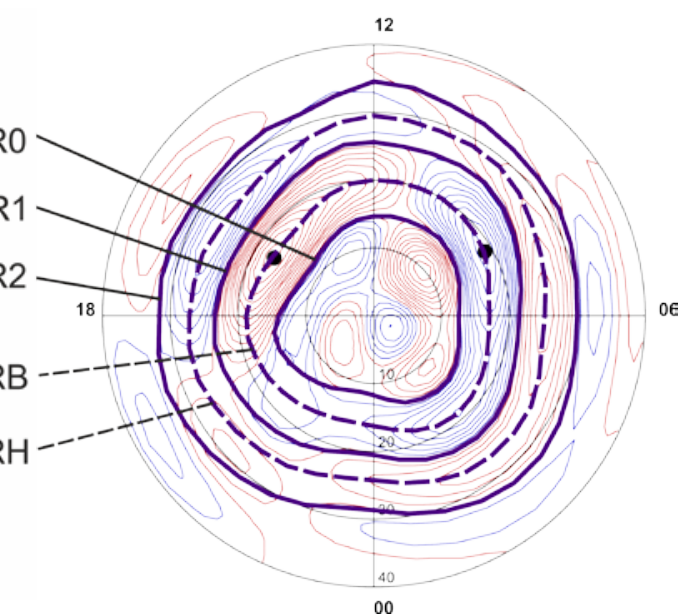


focuses of the current function $J$, and through the respective main focuses of the region 1 FAC density, i.e. coordinates of the main focuses of $J$ and region 1 FAC are almost identical. Often in practice, both in the current function and on region 1 FAC maps there are not two but three or more focuses. Hence, the problem arises of selecting two main focuses.

The main focuses both for the current function $J$ and for the region 1 FAC density should be the largest, rather than be small local extrema. Moreover, coordinates of the main focuses of $J$ and those of region 1 FAC should be roughly equal. Thus, we can formulate a criterion for selecting the main focuses from all possible candidates. The greater the value in the focus of $J$, the larger the value in the focus of FAC; and the smaller the distance between the focuses, the greater the weighting factor

$$
k_{n m}=\frac{i_{\| n} J_{m}}{d_{n m}}
$$

where $i_{\| n}$ is the FAC density value in the $n$th focus; $J_{m}$ is the equivalent current function value in the $m$ th focus; $d_{n m}$ is the distance (orthodromy) between the focuses of the FAC density and those of $J ; k_{n m}$ is the weighting factor for the pair of the $n$th and $m$ th focuses.

According to Formulas (1), (2), in region 1 the FAC density values have the same signs as the current function $J$. There is therefore no need for the absolute value sign in (5), hence the coefficients for region 1 FAC focuses will be positive. When calculating the weighting factors, we perform a preliminary normalization of the FAC density and the function $J$ in the range $[-1 ; 1]$ because they have different orders of magnitude. As a result, by calculating the weighting factors from (5), choose two main focuses with maximum factors: one for the dawn sector of the ionosphere, another for the dusk sector.

\section{Search for boundaries along the principal meridian}

Each of the main focuses we have found has its own colatitude and longitude (principal meridian). Moving from the focus along the principal meridian to the equator and to the pole, we determine the AO boundaries described at the beginning of this section and shown in Figure 1:

$\mathrm{RB}$ - coincides with the focus position;

$\mathrm{R} 1$ - the first sign change (equatorward);

$\mathrm{RH}$ - the first extremum (equatorward);

R0 - the first sign change | the first extremum | half-region (poleward);

$\mathrm{R} 2$ - the first sign change | the first extremum half-region (equatorward);

I is the operational sign indicating "if not found, then".

It might be more difficult to identify R0 and R2 in practice than other boundaries. If a sign change is not found, we utilize an extreme point as a reference point. This is, however, not necessarily successful. In this case, we can determine R0 and R2 from FAC half- regions. Assuming a posteriori that RB divides FAC region 1 approximately in half, we can calculate the colatitude of R0: R0=RB-(R1-RB). Similarly, assuming that $\mathrm{RH}$ divides $\mathrm{FAC}$ region 2 in half, we get $\mathrm{R} 2=\mathrm{RH}+(\mathrm{RH}-\mathrm{R} 1)$.

\section{Search for candidate boundaries on adjacent meridians}

The boundaries found in the vicinity of two main focuses are two segments of the desired full boundaries. At the first stage, these boundary segments match their principal meridian. Each boundary segment determined has two adjacent meridians. Find boundaries on these adjacent meridians. Assuming that RB in the current meridian should not deviate significantly from the boundary in the previous meridian, find its colatitude as the closest extreme value to the colatitude of $\mathrm{RB}$ of the previous meridian. The other boundary candidates for $\mathrm{R} 1, \mathrm{RH}, \mathrm{R} 0, \mathrm{R} 2$ in adjacent meridians are determined in a similar way.

\section{Selection of the next best meridian}

As a rule, in neighboring meridians the boundary does not change sharply. In the polar coordinate system, this feature can be expressed by analogy to the tangent of the tilt angle $\alpha$

$$
\operatorname{tg} \alpha=\left|\frac{\theta_{\mathrm{p}}-\theta_{\mathrm{c}}}{\lambda_{\mathrm{p}}-\lambda_{\mathrm{c}}}\right|,
$$

where $\theta_{\mathrm{p}}, \theta_{\mathrm{c}}$ are colatitudes in the previous and current meridians respectively; $\lambda_{\mathrm{p}}, \lambda_{\mathrm{c}}$ are longitudes in the previous and current meridians respectively.

There are places where we can easily determine a boundary and there is no great change in colatitudes between the current and previous meridians. In such places, the boundary is usually well defined. Thus, from the four meridians with candidate boundaries we can choose one meridian whose boundaries have the smallest difference, calculated from Formula (6). Several boundaries being drawn at a time, it is necessary to calculate the mean tangent for all boundaries of the adjacent meridians, and from them select a meridian with the smallest tangent.

The two boundary segments (dawn and dusk) should merge together to form a single closed boundary. The criterion of the minimum tangent is therefore used not only for adjacent meridians, but also for merging boundary segments.

As a result of the iterative implementation of this step, we obtain the dawn and dusk segments of R0, RB, $\mathrm{R} 1, \mathrm{RH}, \mathrm{R} 2$, which then merge together. If the segments do not merge because of the difficulty in identifying boundaries in the vicinity of the dayside and nightside Harang discontinuities, we interpolate the boundaries. After three-point smoothing, we have final AO boundaries $\mathrm{R} 0, \mathrm{RB}, \mathrm{R} 1, \mathrm{RH}, \mathrm{R} 2$.

The solution procedure is illustrated in Figure 2. 


\section{Search for nightside and dayside Harang discontinuities}

The boundary between positive and negative bays in the horizontal component $\mathbf{H}$ of the disturbed ground-based geomagnetic field in the nightside auroral zone was first discovered by Harang [1946]. Such a reversal of the $\mathbf{H}$ vector is associated with the transition from the eastward electrojet $(\Delta H>0)$ to the westward one $(\Delta H<0)$. Electrojets generally being ionospheric Hall currents, the corresponding rotation was also observed in electric field distributions [Maynard, 1974]. From the analogy of the equivalent current function $J$ and the electric potential $U$, described by Formula (4), in the Northern Hemisphere we have $\nabla J=-\Sigma_{\mathrm{H}} \nabla U$, i.e. $\nabla_{\theta, \lambda} J=\Sigma_{\mathrm{H}} E_{\theta, \lambda}$. Accordingly, to the rotation of the electric field $E_{\mathrm{N}} \rightarrow E_{\mathrm{W}} \rightarrow E_{\mathrm{S}}$ corresponds the change in the gradient of the current function $\left(\nabla_{\theta} J<0\right) \rightarrow\left(\nabla_{\lambda} J<0\right) \rightarrow\left(\nabla_{\theta} J>0\right)$. This means that in the sector of the nightside Harang discontinuity the eastward equivalent current rotates counterclockwise and converts to the westward current [Untiedt, Baumjohann, 1993]. A similar but opposite situation occurs when the auroral electrojets run across on the dayside.

Given the above, the geomagnetic method determines the location of the dayside and nightside Harang discontinuities from changes in the sign of $\nabla_{\theta} J$ at the boundary R1, along which the eastward and westward auroral electrojets flow.

\section{Southern Hemisphere}

The above algorithm of the geomagnetic method for automatic diagnostics of AO boundaries R0, RB, R1, $\mathrm{RH}$, and R2 was first developed for the Northern Hemisphere [Kondratyev et al., 2017; Lunyushkin, Penskikh, 2019]. Extension of MIT to the Southern Hemisphere [Lunyushkin et al., 2019] became possible due to the modern digital database of ground-based geomagnetic data SuperMAG [Gjerloev, 2012] and further studies using the maximum contribution method - the main method for solving MIT system of equations [Penskikh, 2020]. All this allowed us to apply the geomagnetic method of diagnosing AO boundaries to the Southern Hemisphere.

In this paper, the Southern Hemisphere in all Figures is presented as "through Earth", common in the contemporary literature. To facilitate the interhemispheric comparison, colatitudes of Northern and Southern hemispheres and hence colatitudes of all AO boundaries are measured from their respective dipole pole.
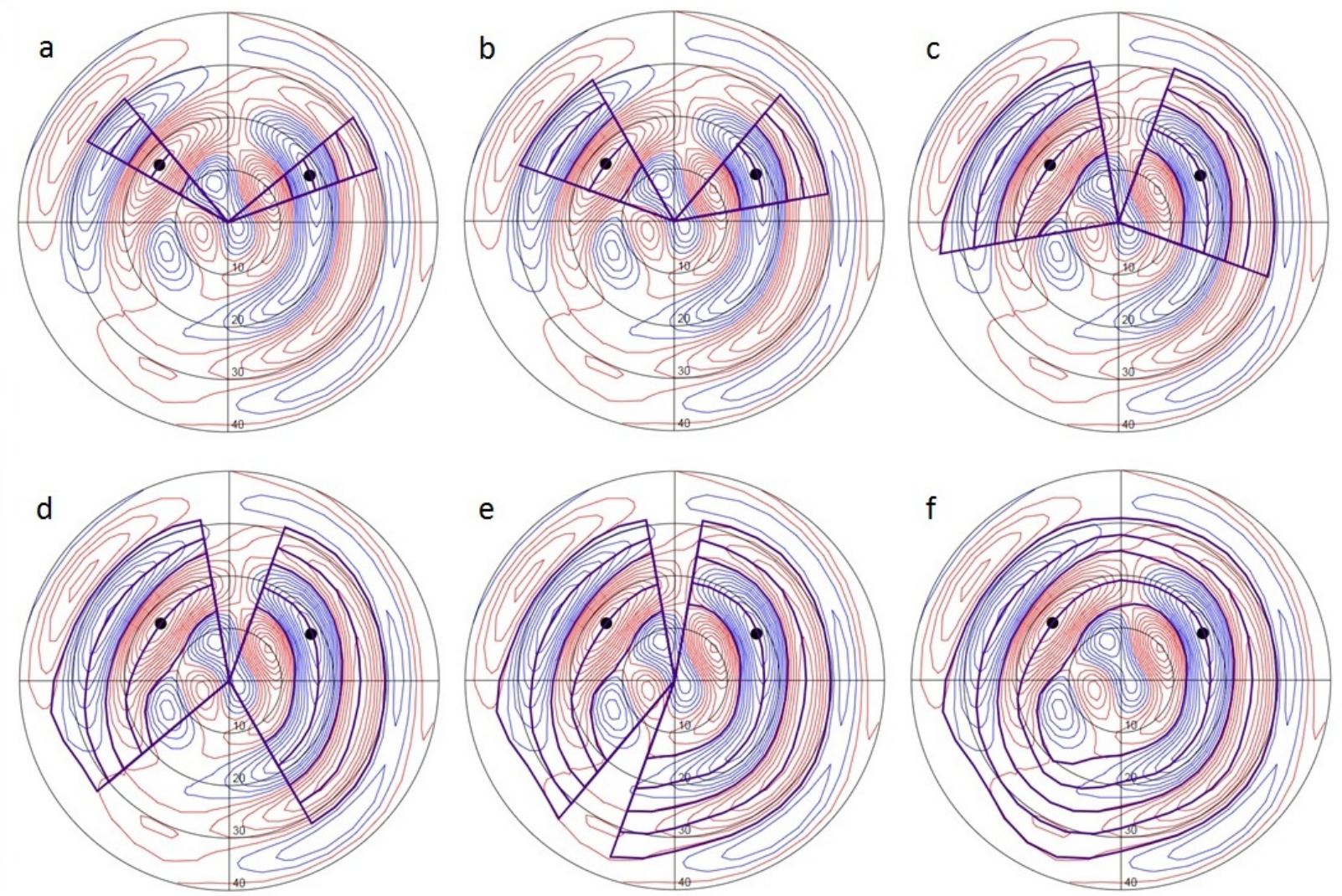

Figure 2. Sequence $(a-f)$ of the algorithm in constructing AO boundaries from FAC density distributions for 03:50 UT on August 27, 2001 


\section{GEOMAGNETIC METHOD TESTING}

The general level of geomagnetic activity in auroral latitudes is largely assessed using the $A E$ index, which is also utilized in most studies for timing of magnetic substorm main phases. However, the new auroral index SME [Newell, Gjerloev, 2011], which is an improved analog of the $A E$ index, is gaining popularity. $S M E$ is distinguished, firstly, by a large number of stations used for its calculation (up to 130 in SME and only 12 in $A E$ ) and, secondly, by an intellectual original method for determining base lines of the geomagnetic field at all ground magnetic stations and by regular cleaning of all raw geomagnetic data from various errors detected [Gjerloev, 2012]. The SME index allows us, for example, to much more accurately determine the beginning of the substorm expansion phase [Newell, Gjerloev, 2014].

In this section, we demonstrate the efficiency of the automatic method of determining $\mathrm{AO}$ boundaries in two hemispheres with the example of the August 27, 2001 isolated substorm, previously examined in depth in [Baker et al., 2005; Mishin et al., 2017]. We have chosen this event also because of the availability of simultaneous satellite observations (IMAGE) and output data, suitable for comparison, from some models (SuperDARN, OVATION, APM). Figure 3 plots variations of the geomagnetic activity index in the auroral oval
(SME), z component of the interplanetary magnetic field (IMF $B_{z}$ ), and magnetic fluxes through the north and south polar caps - the parameters characterizing the development of the August 27, 2001 substorm between 03:00 and 06:00 UT. The magnetic fluxes were calculated at an altitude of $115 \mathrm{~km}$ by integrating the dipole geomagnetic field over the region on a sphere bounded by respective boundaries RB. For each of the substorm main phases, timed in [Mishin et al., 2017], we select three characteristic points in time (dashed lines in Figure 3) and demonstrate with this example the capabilities of our ground-based geomagnetic method for automatic diagnostics of $\mathrm{AO}$ boundaries in two hemispheres from MIT output data.

\section{Comparison between the automatic and man- ual methods}

It is necessary first to correctly assess the efficiency and accuracy of the method of determining AO boundaries in two hemispheres, excluding possible MIT errors. To do this, for each hemisphere we compare the AO boundaries (R0, RB, R1, RH, R2) determined by the automatic method with those determined manually. Figures 4 and 5 show that for the three selected points in time in both the Northern and Southern hemispheres,
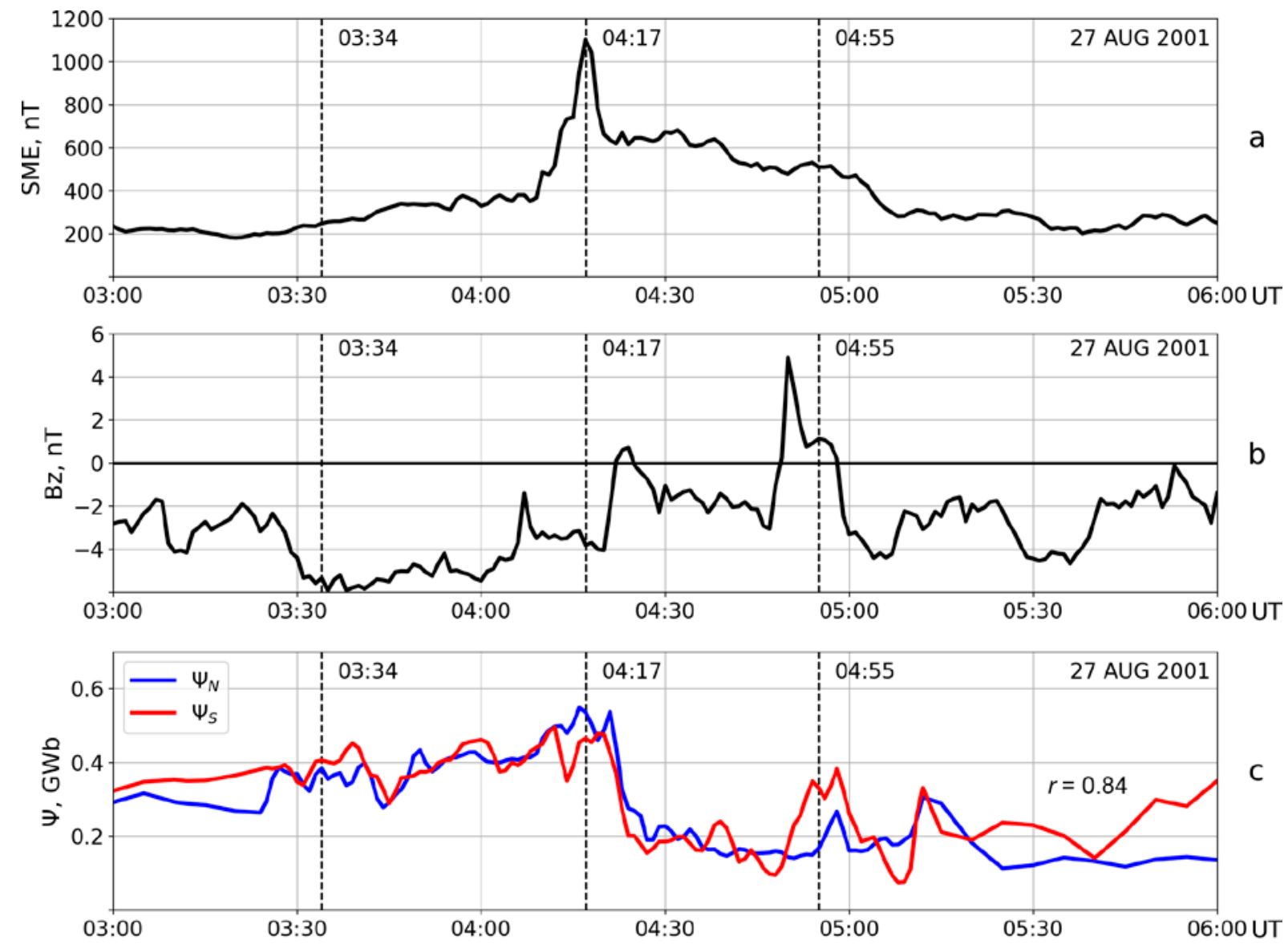

Figure 3. Variations in the auroral index SME (a), IMF $B_{\mathrm{z}}(b)$, and magnetic fluxes $\Psi(c)$ through PC of the Northern $\left(\Psi_{N}\right)$ and Southern $\left(\Psi_{S}\right)$ hemispheres during the August 27, 2001 substorm, characteristic time points of which are indicated by dashed lines: 03:34 UT — growth phase, 04:17 UT — expansion phase, 04:55 UT — recovery phase 


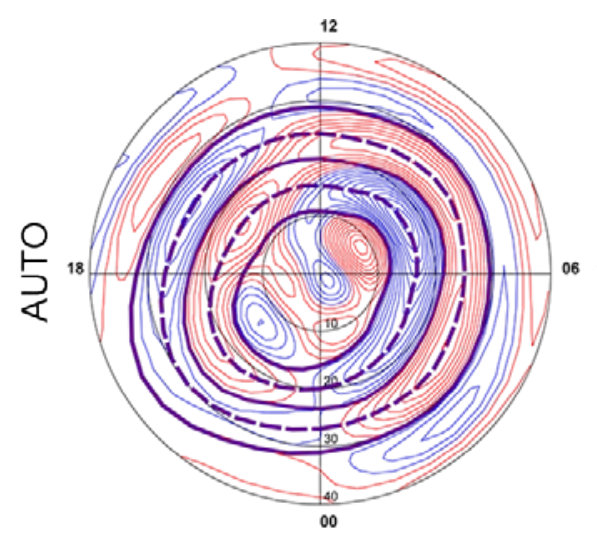

growth phase, 03:34UT

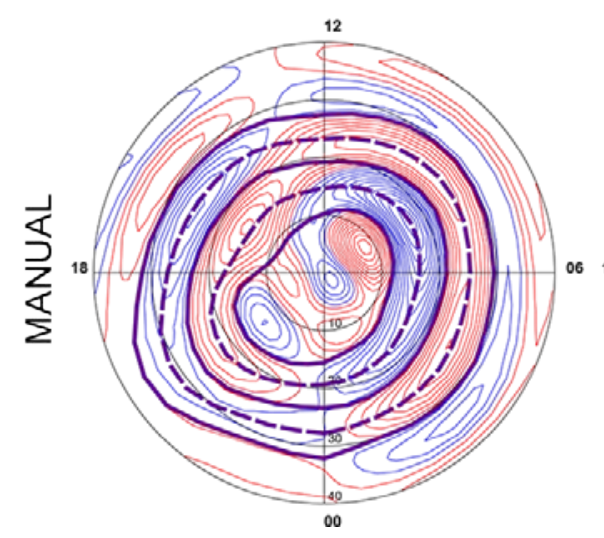

Figure 4. Comparison between boundaries for the Northern Hemisphere. The top row shows boundaries determined by the automatic method; the bottom row, those determined manually. In columns are three characteristic time points for three phases of the August 27, 2001 substorm

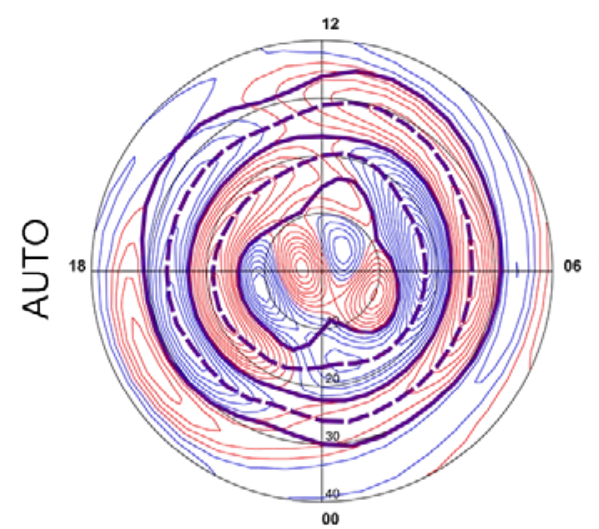

growth phase, 03:34UT

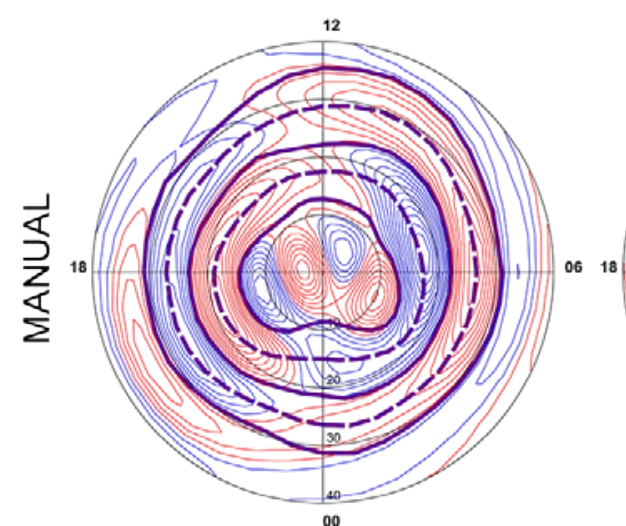

Figure 5. The same as in Figure 4 for the Southern Hemisphere

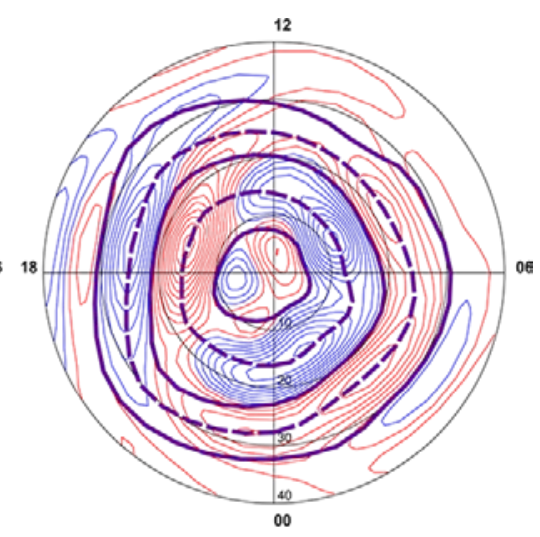

recovery phase, 04:55UT

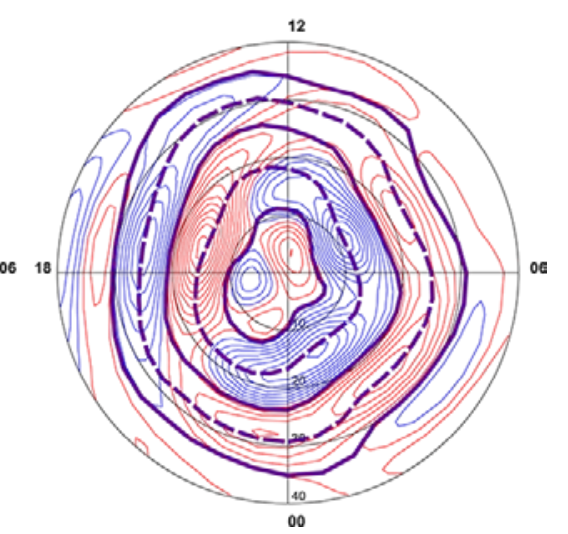

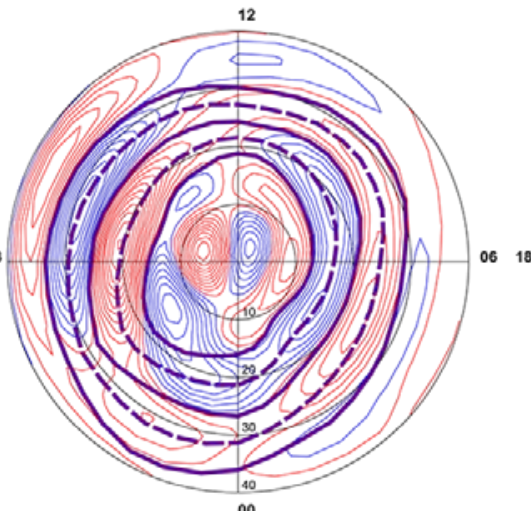

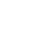


there is good qualitative agreement between all respective boundaries determined automatically and manually.

A quantitative statistical estimate of the accuracy of the automatic method for diagnosing $\mathrm{AO}$ boundaries in two hemispheres is shown in Figure 6 with an example of convection reversal boundary RB. When constructing the plots for each hemisphere, we have used 80 time points spanning a three-hour interval of the substorm considered. For clarity, datum points are grouped to the nearest node on the grid; the diameter of each circle in the Figure is proportional to the number of points in the group. Plots for other AO boundaries (R0, R1, RH, R2) are similar to those in Figure 6 for each hemisphere and therefore are omitted here. Figure 6 indicates that densities of the points lie predominantly on the main diagonal of the Figure, and an rms error is $\sim 2^{\circ}$ (two steps of the computation grid in latitude in MIT) at medium correlation between the data compared.

Note that here we proceed from the assumption that an expert has absolutely correctly determined the boundaries. However, this is not quite true. Firstly, in the case of re-drawing the boundaries a man cannot draw exactly the same boundaries, i.e. there is always a natural error due to anatomical features of the human hand. Secondly, there are places, especially in the vicinity of Harang discontinuities, where boundaries cannot be drawn unambiguously [Iijima, Potemra, 1978; Coxon et al., 2018; Xiong et al., 2020].

\section{Comparison of auroral oval boundaries with those obtained by other methods}

In Introduction, we have mentioned a number of ground- and satellite-based facilities and methods for observing AO and diagnosing its main boundaries, including such major projects as IMAGE, SuperDARN, and OVATION, data from which we use in this section

RB, Northern Hemisphere

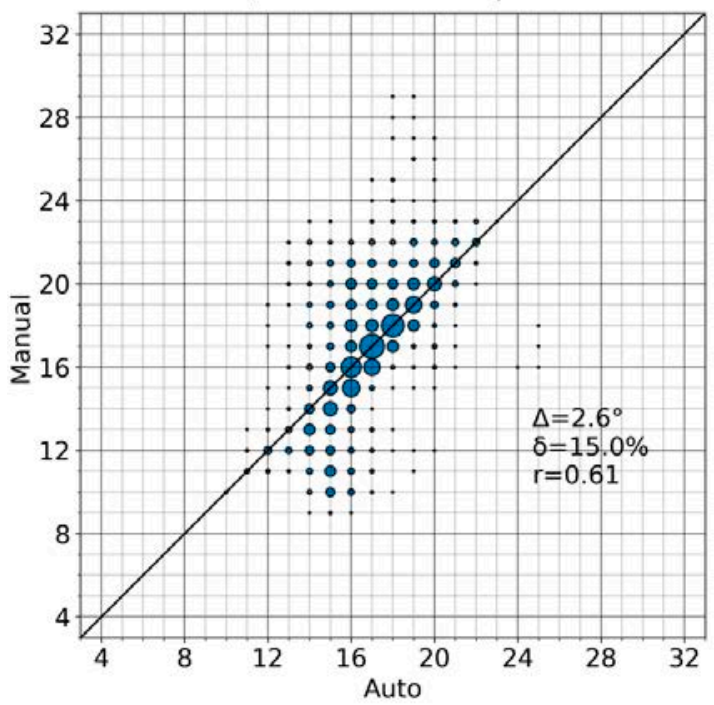

for comparison with the results of diagnostics of the $\mathrm{AO}$ boundaries obtained by the geomagnetic method.

Figure 7 presents results of the comparison. The second top panel displays images of the auroral oval in the Northern Hemisphere captured by the satellite IMAGE for the three selected time points at different phases of the August 27, 2001 magnetic substorm. We took these images from the SuperMAG open source site [https://supermag.jhuapl.edu]. The boundaries R0, RB, and R2 from the top panel, where the AO boundaries of the Northern Hemisphere were obtained by the automatic geomagnetic method from FAC distributions, are superimposed on these images. In general, we can note a good qualitative agreement of the main AO boundaries $\mathrm{R} 0$ and $\mathrm{R} 2$ obtained by our method with aurorae from IMAGE data for all three substorm phases. The center of the auroral oval is displaced to the right relative to the PC center - this may be explained by the fact that the upward FAC (precipitating electrons) in the dusk sector is located in FAC region 1 in the polar region of $\mathrm{AO}$; and in the dawn sector, in FAC region 2, i.e., in the subequatorial part of AO. The third and fourth panels in Figure 7 illustrate a similar comparison of $\mathrm{AO}$ boundaries (R0, RB, and R2) obtained by the geomagnetic method with AO images calculated respectively by the models OVATION-prime [https://sourceforge.net/projects/ovation-prime/?source =typ_redirect] and APM [http://apm.pgia.ru/webtool/ frontend]. Also noteworthy here is a good qualitative agreement of our AO boundaries with the aforementioned models.

Figure 8 depicts distributions of electric potentials in the high-latitude ionosphere derived from the SuperDARN-RG96 model for the Northern and Southern hemispheres during three phases of the August

Figure 6. Statistical comparison between the automatic and manual methods of determining convection reversal boundaries RB for the August 27, 2001 substorm for the Northern (left) and Southern (right) hemispheres. X-and Y-axes show colatitudes of respective boundaries 


\section{growth phase, 03:34UT}
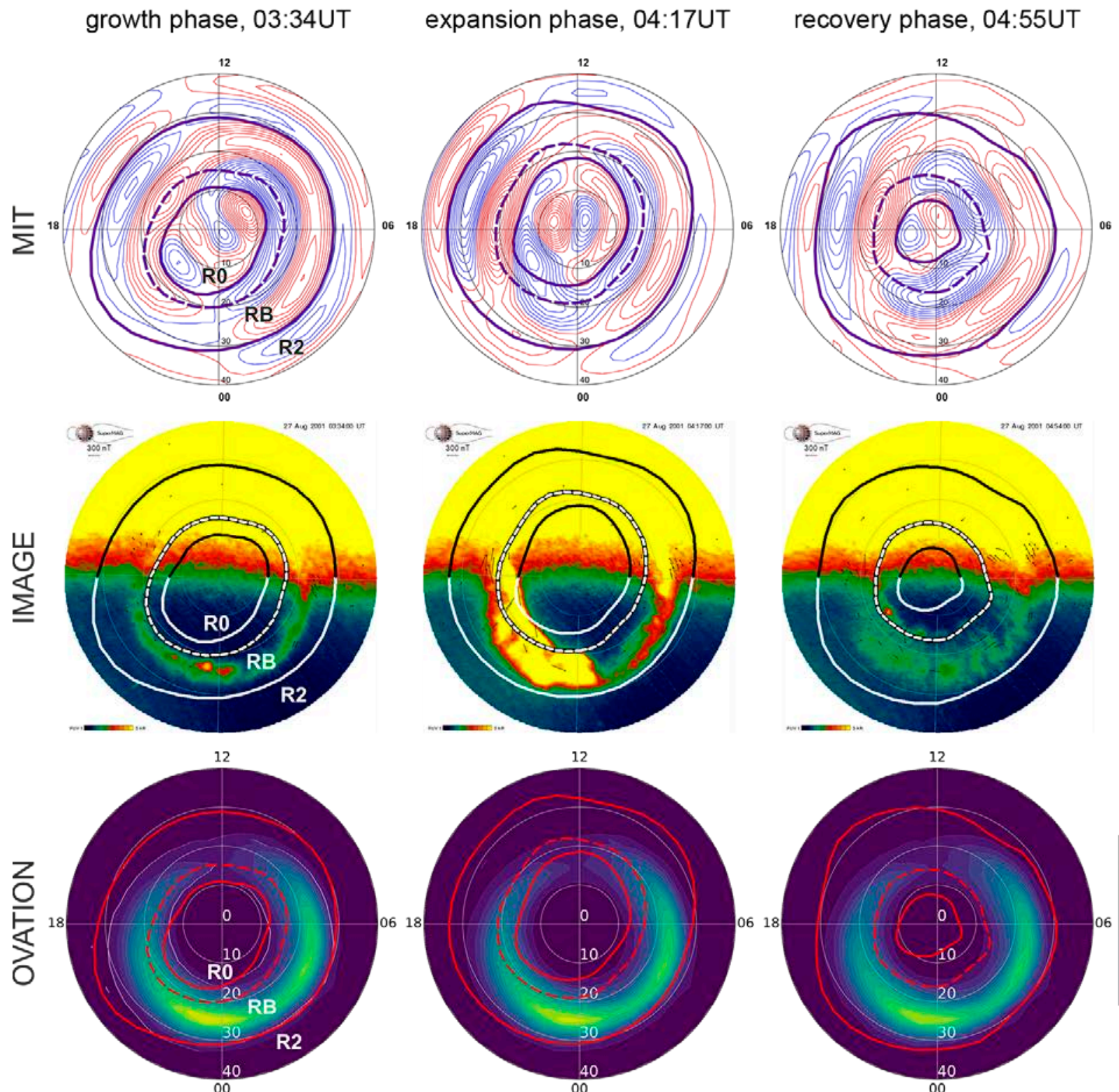

$\operatorname{Min}=0.0 \quad \operatorname{Max}=2.95$ Step $=0.2$

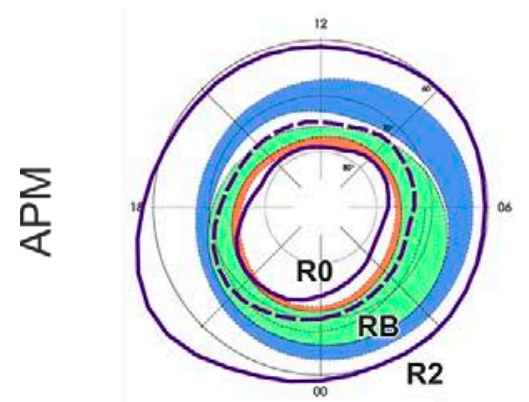

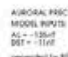

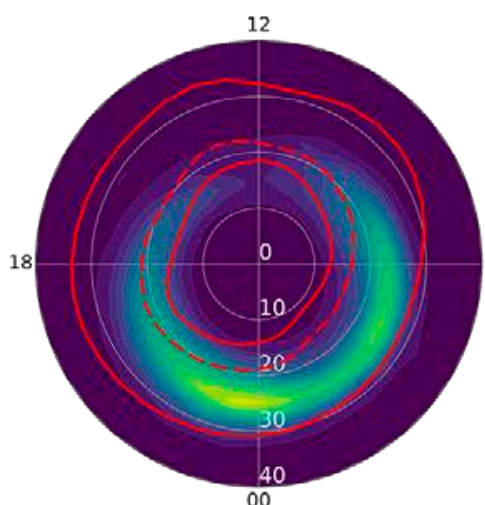

$\operatorname{Min}=0.0 \quad \operatorname{Max}=2.88 \quad \mathrm{Step}=0.2$

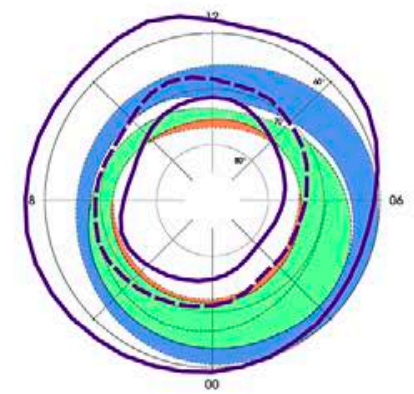

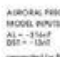

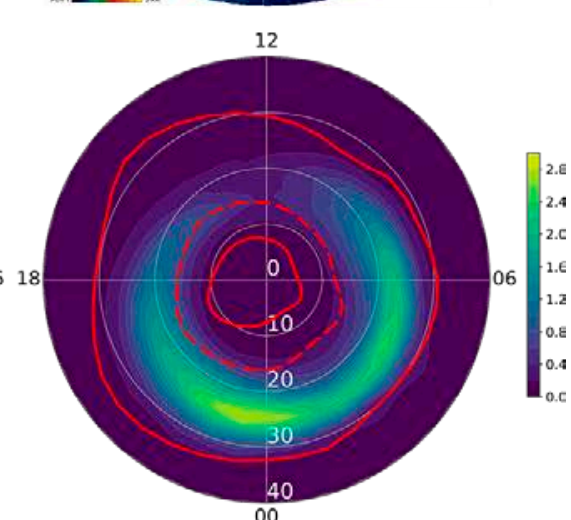

$\operatorname{Min}=0.0 \quad$ Max $=2.79$ Step $=0.2$

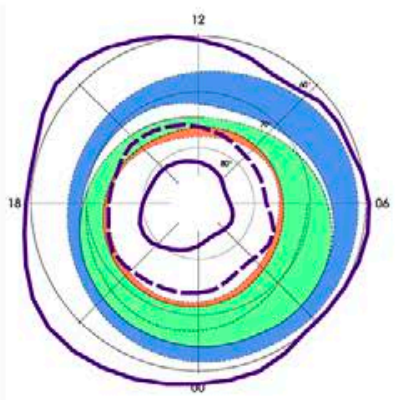

cosing

Figure 7. Three phases of the August 27, 2001 substorm in the Northern Hemisphere. AO boundaries (R0, RB, R2) determined by the automatic geomagnetic method from MIT FAC density distributions versus aurorae from IMAGE satellite data and AO from the OVATION and APM models; R0, RB, R2 from the top panel are superimposed on bottom panels 

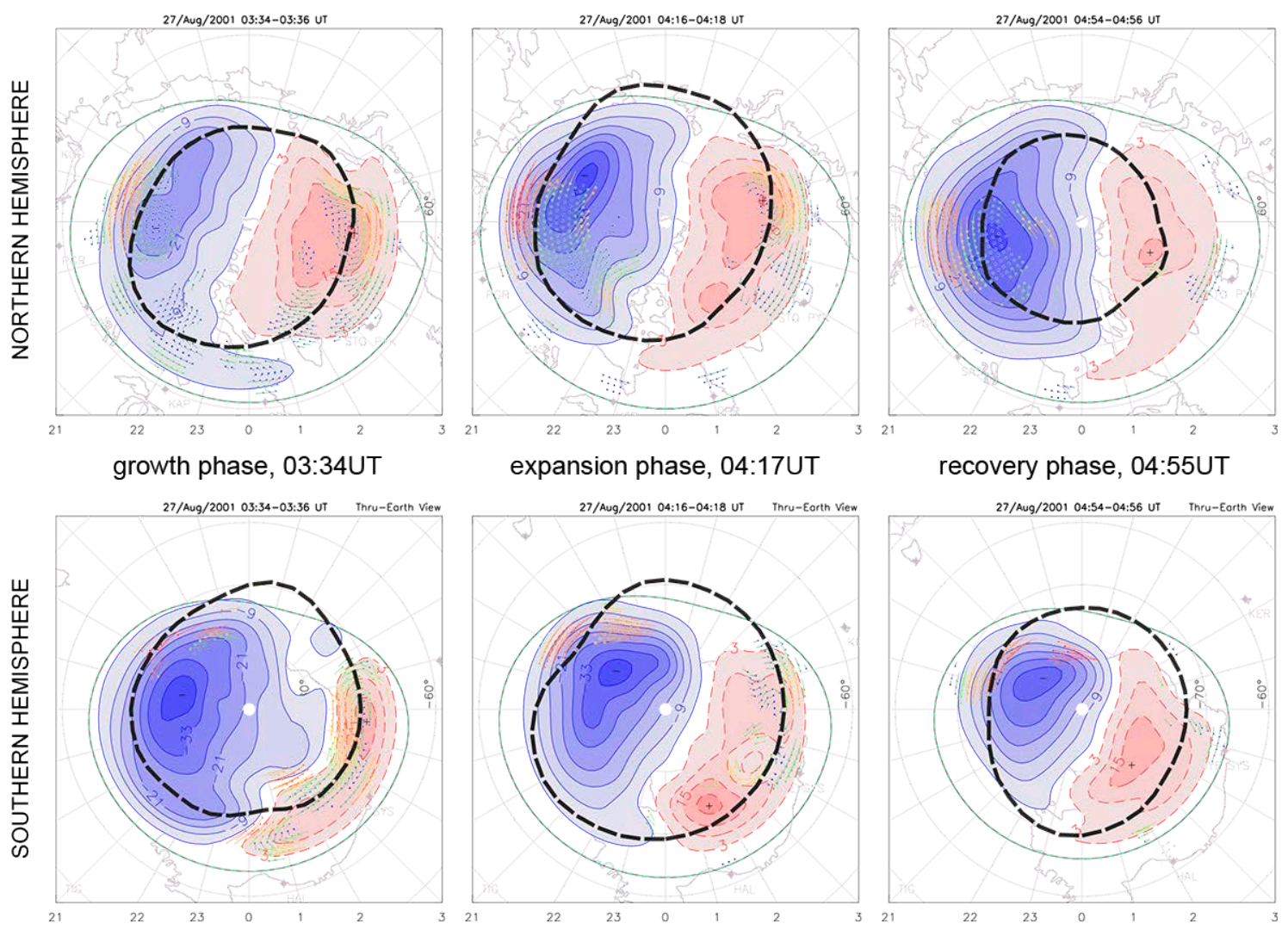

Figure 8. Ionospheric convection reversal boundaries RB (thick dashed line) determined by the geomagnetic method in the Northern (top) and Southern (bottom) hemispheres for three phases of the August 27, 2001 substorm versus respective electric potential maps from the SuperDARN-RG96 model

27, 2001 magnetic substorm, which are superimposed by the ionospheric convection reversal boundaries $\mathrm{RB}$ determined by our automatic geomagnetic method. We can see that in the Northern Hemisphere there is a fairly good qualitative agreement between the model electric potential and the convection reversal boundary according to MIT: RB virtually passes through two main focuses of the electric potential of the RG96 model. In the Southern Hemisphere, in particular in the dusk sector, the agreement between RB and the electric potential is somewhat worse. This difference might be due to the fact that during the event of interest in the Southern Hemisphere there were a smaller number of instruments than in the Northern Hemisphere: 6 to 10 for SuperDARN radars [http://vt.superdarn.org/tiki-index.php?page=Radar+

Overview], 30 to 149 for ground-based magnetometers [http://supermag.jhuapl.edu]. It is well known that the insufficiently dense network of ground-based observations significantly affects the accuracy in solving interpolation problems of both geomagnetic [Rigler et al., 2019] and radar measurements [Ruohoniemi, Baker, 1998].

\section{Polar cap dynamics during an isolated substorm}

In Introduction, we have noted that PC of each hemisphere is an ionospheric projection corresponding to the open magnetotail lobe. Many studies have estab- lished that an isolated magnetospheric substorm is well described by a classical three-phase Dungey cycle [Akasofu, 1977, 2013; Cowley, Lockwood, 1992; Milan et al., 2007, Akasofu, 2013]. During the growth phase, magnetic energy is accumulated in the magnetotail, with the PC area increasing in the polar ionosphere [Russell, McPherron, 1973; Akasofu, 1977; Kamide et al., 1999]. Magnetic reconnection in nearEarth plasma sheet [Baker et al., 1996] initiates the substorm expansion phase during which and then during the recovery phase the substorm energy is provided by the accumulated magnetic energy release, which in the adjacent ionospheric region is observed as a decrease in the PC area [Kamide et al., 1999; Milan et al., 2003, 2007]. Exactly this PC behavior — an increase during the growth phase and a decrease during the recovery phase - is illustrated in Figure 4, as for R0 and RB in the Northern Hemisphere, determined both manually and automatically. A similar picture emerges in the Southern Hemisphere (see Figure 5), which can be easily explained physically. First, if the magnetosphere is considered in the assumption of highly stretched but closed field lines of tail lobes [Heikkila, 2011], it represents a complete structure, therefore an increase in the magnetic flux and magnetotail length equally influences the northern and southern lobes, and hence their projections - PC in two hemispheres. Second, during this isolated substorm the main contribution to the mechanism of dayside reconnection [Dungey, 1961; Milan et al., 2007] was made by IMF 
$B_{\mathrm{z}}$, which is obviously equally affects the entire magnetosphere, i.e. equally "opens" tail lobes of the Northern and Southern hemispheres. Such a synchronous change in the tail lobes of two hemispheres is confirmed in boundaries R0 and dynamics of magnetic fluxes through the north and south PC, obtained by the geomagnetic method (see Figure 3 ).

Note that the synchronous dynamics of magnetic fluxes through PC of two hemispheres has been determined by the manual geomagnetic method for the August 17, 2001 magnetic storm [Lunyushkin et al., 2019].

The main unloading of the accumulated magnetic energy of the tail occurs during the magnetospheric substorm expansion phase [Akasofu, 1977; Mishin et al., 2017]. A change in the PC area during the expansion phase is not always unambiguous and depends on the balance of the energy coming into the magnetosphere and its release into the energy of auroral particles, ionosphere heating, ring current, etc. [Milan et al., 2003, 2007]. During the expansion phase, the PC area usually decreases, but if $B_{z}$ is negative, the PC area may still increase slightly [Kamide et al., 1999]. This is what happened during the magnetospheric substorm on August 27, 2001 (see Figures 3-5). Figure 9 shows a low interhemispheric correlation between the PC boundaries. Note that this fact had no effect on PC areas of the two hemispheres and on magnetic fluxes through them. The high interhemispheric correlation between magnetic fluxes through PC $(r=0.84$, Figure $3, c)$ confirms the expected synchronization of Dungey cycle reconnection processes in northern and southern magnetotail lobes.

\section{CONCLUSION}

In this study, we have continued the development of the new ground-based method of automatic diagnostics of AO boundaries, initiated in [Lunyushkin, Penskikh, 2019], on the basis of MIT output data and have extended it to the Southern Hemisphere. Using analysis of a

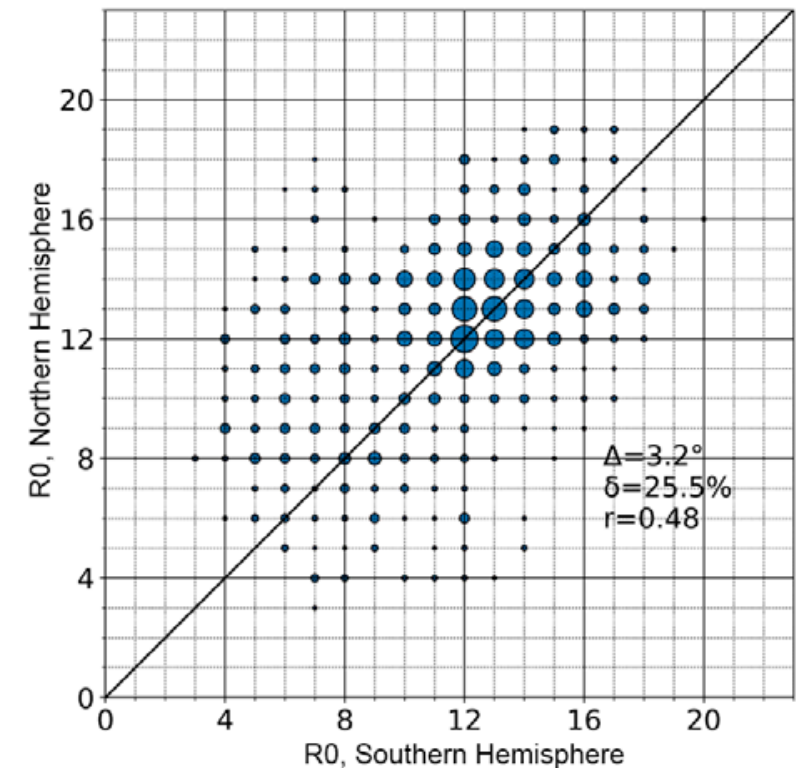

substorm as an example, we have shown that the accuracy of automatic method of determining AO boundaries in two hemispheres is highly competitive with the manual method. Implementation of the geomagnetic method of automatic diagnostics of $\mathrm{AO}$ boundaries in two hemispheres has been included in the MIT software package as an important module. The geomagnetic method of determining AO boundaries, like the entire updated MIT software package, now enables us to do instantaneous calculations in both hemispheres automatically, without active human involvement.

The paper has shown the following: the AO boundaries determined by the geomagnetic method are qualitatively consistent with simultaneous auroral oval images from the IMAGE satellite, as well as with the OVATION and APM results; the ionospheric convection reversal boundary found by the geomagnetic method in two hemispheres is consistent with the ionospheric electric potential maps from the SuperDARN-RG96 model.

We have confirmed the practical significance of the geomagnetic method of diagnosing PC boundaries, using the isolated substorm selected as an example, by the fact of a synchronous change of PC in two hemispheres and of magnetic fluxes through them during three substorm phases.

Our geomagnetic method of automatic diagnostics of AO boundaries in ionospheres of two hemispheres from data acquired by the global ground-based network of magnetometers is a new and promising instrument for studying the interaction in the solar wind - magnetosphere - ionosphere system and for addressing the topical problem of magnetospheric substorms.

Unlike radars, satellites, and GPS, the SuperMAG database we use contains longer time series of continuous measurements of the geomagnetic variation field. The updated magnetogram inversion technique developed at ISTP SB RAS has sufficiently high spatial and temporal

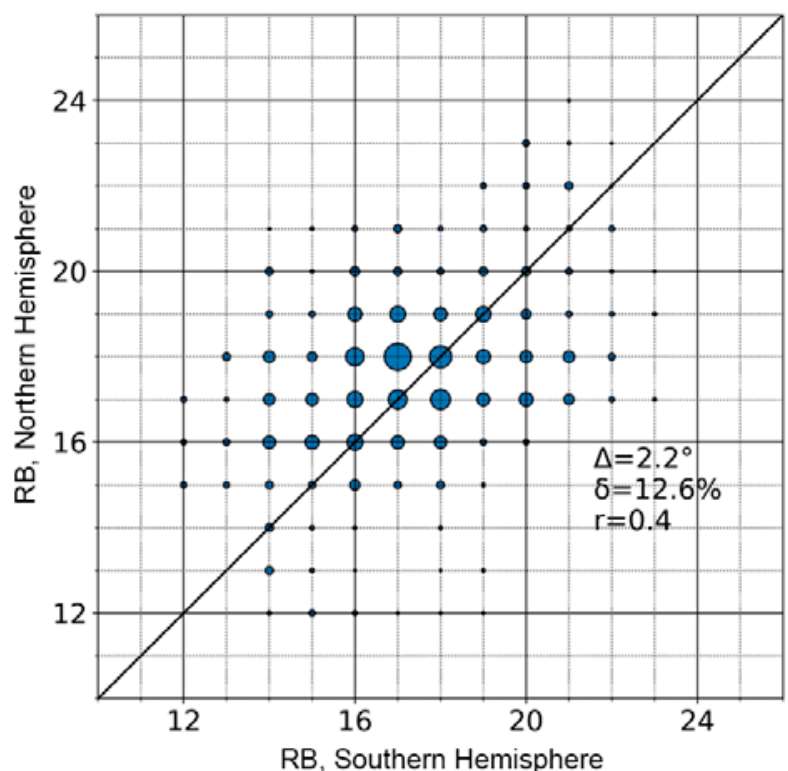

Figure 9. Statistical interhemispheric comparison between boundaries for R0 (left) and RB (right) determined by the automatic method for the August 27, 2001 substorm. X- and Y-axes show colatitudes of respective boundaries 
resolution and provides an instantaneous large-scale structure of equivalent currents, electric fields, and fieldaligned currents simultaneously in two hemispheres. Moreover, this technique is much cheaper than other instruments.

We thank V.V. Mishin, A.V. Tashchilin, V.G. Vorobev, O.I. Yagodkina, and A.G. Yakhnin for interesting discussions and helpful comments on the main results of this paper at the 43rd annual seminar "Physics of Auroral Phenomena" (PGI KSC RAS, March 2020).

We express our gratitude to creators of SuperMAG [https://supermag.jhuapl.edu], APM [http://apm.pgia.ru/webtool/frontend ], SuperDARNRG96 [http://supermag.jhuapl.edu], OVATION [https://sourceforge.net/projects/ovation-prime/?source= typ_redirect], OMNI [https://omniweb.gsfc.nasa.gov/ form/omni_min.html] for the access to these databases and models.

The work was financially supported by RFBR under research project No. 19-35-90046.

\section{REFERENCES}

Akasofu S.-I. Polar and Magnetospheric Substorms. Dordrecht, Springer Netherlands, 1968, 292 p. DOI: 10.1007/97894-010-3461-6.

Akasofu S.-I. Physics of Magnetospheric Substorms. Dordrecht, Springer Netherlands, 1977, 619 p. DOI: 10.1007/97894-010-1164-8.

Akasofu S.-I. The relationship between the magnetosphere and magnetospheric/auroral substorms. Ann. Geophys. 2013, vol. 31, no. 3, pp. 387-394. DOI: 10.5194/angeo-31-3872013.

Baker D.N., Pulkkinen T.I., Angelopoulos V., Baumjohann W., McPherron R.L. Neutral line model of substorms: Past results and present view. J. Geophys. Res.: Space Phys. 1996, vol. 101, no. A6, pp. 1297-13010. DOI: 10.1029/95ja03753.

Baker D.N., McPherron R.L., Dunlop M.W. Cluster observations of magnetospheric substorm behavior in the nearand mid-tail region. Adv. Space Res. 2005, vol. 36, no. 10, pp. 1809-1817. DOI: 10.1016/j.asr.2004.04.021.

Bazarzhapov A.D., Matveev M.I., Mishin V.M. Geomagnetic variations and storms. Novosibirsk, Nauka Publ., 1979, 248 p. (In Russian).

Boakes P.D., Milan S.E., Abel G.A., Freeman M.P., Chisham G., Hubert B., Sotirelis T. On the use of IMAGE FUV for estimating the latitude of the open/closed magnetic field line boundary in the ionosphere. Ann. Geophys. 2008, vol. 26, no. 9, pp. 2759-2769. DOI: 10.5194/angeo-26-27592008.

Burrell A.G., Chisham G., Milan S.E., Kilcommons L., Chen Y.J., Thomas E.G., Anderson B. AMPERE polar cap boundaries. Ann. Geophys. 2020, vol. 38, no. 2, pp. 481-490. DOI: 10.5194/angeo-38-481-2020.

Carter J.A., Milan S.E., Coxon J.C., Walach M.T., Anderson B.J. Average field-aligned current configuration parameterised by solar wind conditions. J.Geophys. Res.: Space Phys. 2016, vol. 121, no. 2, pp. 1294-1307. DOI: 10.1002/ 2015ja021567.

Coley W.R. Spatial relationship of field-aligned currents, electron precipitation, and plasma convection in the auroral oval. J. Geophys. Res.: Space Phys. 1983, vol. 88, no. A9, pp. 7131-7141. DOI: 10.1029/JA088iA09p07131.

Cowley S.W.H., Lockwood M. Excitation and decay of solar-wind driven flows in the magnetosphere-ionosphere system. Ann. Geophys. 1992, vol. 10, pp. 103-115.

Coxon J.C., Milan S.E., Anderson B.J. A review of Birkeland current research using AMPERE. Electric Currents in Geospace and Beyond. Ed. by A. Keiling et al., Hoboken, New Jersey, USA, Wiley-AGU, 2018, pp. 259-278. DOI: 10.1002/ 9781119324522.ch16.

Dungey J.W. Interplanetary Magnetic Field and the Auroral Zones. Phys. Rev. Lett. 1961, vol. 6, no. 2, pp. 47-48. DOI: 10.1103/PhysRevLett.6.47.

Feldstein Y.I. Auroral morphology, I. Auroral and geomagnetic disturbances. Tellus. 1964, vol. 16, no. 2, pp. 252 257. DOI: 10.3402/tellusa.v16i2.8897.

Feldstein Y.I., Galperin Y.I. The auroral luminosity structure in the high-latitude upper atmosphere: Its dynamics and relationship to the large-scale structure of the Earth's magnetosphere. Rev. Geophys. 1985, vol. 23, no. 3, pp. 217275. DOI: 10.1029/RG023i003p00217.

Feldstein Y.I., Shevnin A.D., Starkov G.V. Auroral oval and magnetic field in the tail of the magnetosphere. Proc. the Birkeland Symposium on Aurora and Magnetic Storms. September 18-22, 1967, Sandefjord, Norway. Ed. by A. Egeland, J.A. Holtet, Paris, Centre National de la Recherche Scientifique, 1968, pp. 43-45.

Fujii R., Hoffman R.A., Sugiura M. Spatial relationships between region 2 field-aligned currents and electron and ion precipitation in the evening sector. J. Geophys. Res.: Space Phys. 1990, vol. 95, no. A11, pp. 18939-18947. DOI: 10.1029/ JA095iA11p18939.

Gary J.B., Zanetti L.J., Anderson B.J., Potemra T.A., Clemmons J.H., Winningham J.D., Sharber J.R. Identification of auroral oval boundaries from in situ magnetic field measurements. J. Geophys. Res.: Space Phys. 1998, vol. 103, no. A3, pp. 4187-4197. DOI: 10.1029/97ja02395.

Gjerloev J.W. The SuperMAG data processing technique. $J$. Geophys. Res.: Space Phys. 2012, vol. 117, no. A9, pp. A09213. DOI: 10.1029/2012ja017683.

Harang L. The mean field of disturbance of polar geomagnetic storms. Terrestrial Magnetism and Atmospheric Electricity. 1946, vol. 51, no. 3, pp. 353-380. DOI: 10.1029/ TE051i003p00353.

Heikkila W.J. Earth's Magnetosphere: Formed by the Low-Latitude Boundary Layer. Amsterdam, Elsevier, 2011, 535 p. DOI: 10.1016/C2009-0-05888-7.

Heppner J.P. Electric field variations during substorms: OGO-6 measurements. Planetary Space Sci. 1972, vol. 20, no. 9, pp. 1475-1498. DOI: 10.1016/0032-0633(72)90052-9.

Iijima T., Potemra T.A. Large-scale characteristics of field-aligned currents associated with substorms. $J$. Geophys. Res.: Space Phys. 1978, vol. 83, no. A2, pp. 599615. DOI: 10.1029/JA083iA02p00599.

Jones A.V. Aurora. Dordrecht, Netherlands, Springer, 1974, 304 p. DOI: 10.1007/978-94-010-2099-2.

Kamide Y., Kokubun S., Bargatze L.F., Frank L.A. The size of the polar cap as an indicator of substorm energy. Physics and Chemistry of the Earth. Part C: Solar, Terrestrial and Planetary Science. 1999, vol. 24, no. 1-3, pp. 119-127. DOI: 10.1016/s1464-1917(98)00018-x.

Khorosheva O.V. Spatial-temporal distribution of auroras. Moscow, Nauka Publ., 1967, 84 p. (In Russian).

Kondratyev A.B., Penskikh Yu.V., Lunyushkin S.B. Automated method for determining auroral oval boundaries, based on the magnetogram inversion technique. Baikal Young Scientists' International School on Fundamental Physics: Proc. XV Young Scientists'Conference "Interaction of Fields and Radiation with Matter". Irkutsk, 11-16 September 2017. Irkutsk, ISTP SB RAS, 2017, pp. 107-112. (In Russian). 
Korth H., Zhang Y., Anderson B.J., Sotirelis T., Waters C.L. Statistical relationship between large-scale upward field-aligned currents and electron precipitation. J. Geophys. Res.: Space Phys. 2014, vol. 119, no. 8, pp. 6715-6731. DOI: 10.1002/ 2014ja019961.

Longden N., Chisham G., Freeman M.P., Abel G.A., Sotirelis T. Estimating the location of the open-closed magnetic field line boundary from auroral images. Ann Geophys. 2010, vol. 28, no. 9, pp. 1659-1678. DOI: 10.5194/angeo-28-1659-2010.

Lu G., Reiff P.H., Hairston M.R., Heelis R.A., Karty J.L. Distribution of convection potential around the polar cap boundary as a function of the interplanetary magnetic field. $J$. Geophys. Res.: Space Phys. 1989, vol. 94, no. A10, pp. 1344713461. DOI: 10.1029/JA094iA10p13447.

Lunyushkin S.B., Mishin V.V., Karavaev Y.A., Penskikh Y.V., Kapustin V.E. Studying the dynamics of electric currents and polar caps in ionospheres of two hemispheres during the August 17, 2001 geomagnetic storm. Solar-Terr. Phys. 2019, vol. 5, no. 2, pp. 15-27. DOI: 10.12737/stp-52201903.

Lunyushkin S.B., Penskikh Y.V. Diagnostics of the auroral oval boundaries on the basis of the magnetogram inversion technique. Solar-Terr. Phys. 2019, vol. 5, no. 2, pp. 88-100. DOI: $10.12737 /$ stp-52201913.

Maynard N.C. Electric field measurements across the Harang discontinuity. J. Geophys. Res. 1974, vol. 79, iss. 31, pp. 4620-4631. DOI: 10.1029/JA079i031p04620.

Milan S.E., Lester M., Cowley S.W.H., Oksavik K., Brittnacher M., Greenwald R.A., Sofko G., Villain J.P. Variations in the polar cap area during two substorm cycles. Ann. Geophys. 2003, vol. 21, no. 5, pp. 1121-1140. DOI: 10.5194/angeo-21-1121-2003.

Milan S.E., Provan G., Hubert B. Magnetic flux transport in the Dungey cycle: A survey of dayside and nightside reconnection rates. J. Geophys. Res.: Space Phys. 2007, vol. 112, no. A1, pp. A01209. DOI: 10.1029/2006ja011642.

Milan S.E., Hutchinson J., Boakes P.D., Hubert B. Influences on the radius of the auroral oval. Ann. Geophys. 2009, vol. 27, no. 7, pp. 2913-2924. DOI: 10.5194/angeo-272913-2009.

Mishin V.M. The magnetogram inversion technique and some applications. Space Sci. Rev. 1990, vol. 53, no. 1-2, pp. 83-163. DOI: 10.1007/bf00217429.

Mishin V.M., Lunyushkin S.B., Shirapov D.S., Baumjohann W. A new method for generating instantaneous ionospheric conductivity models using ground-based magnetic data. Planet. Space Sci. 1986, vol. 34, no. 8, pp. 713-722. DOI: 10.1016/0032-0633(86)90125-x.

Mishin V.M., Bazarzhapov A.D., Saifudinova T.I., Lunyushkin S.B., Shirapov D.S., Woch J., Eliasson L., Opgenoorth H., Murphree J.S. Different methods to determine the polar cap area. J. Geomagnetism and Geoelectricity. 1992, vol. 44, no. 12, pp. 1207-1214. DOI: 10.5636/jgg.44.1207.

Mishin V.M., Mishin V.V., Lunyushkin S.B., Wang J.Y., Moiseev A.V. 27 August 2001 substorm: Preonset phenomena, two main onsets, field-aligned current systems, and plasma flow channels in the ionosphere and in the magnetosphere. J. Geophys. Res.: Space Phys. 2017, vol. 122, no. 5, pp. 4988-5007. DOI: 10.1002/2017ja023915.

Newell P.T., Gjerloev J.W. Evaluation of SuperMAG auroral electrojet indices as indicators of substorms and auroral power. J. Geophys. Res.: Space Phys. 2011, vol. 116, no. A12, pp. A12211. DOI: 10.1029/2011ja016779.
Newell P.T., Gjerloev J.W. Local geomagnetic indices and the prediction of auroral power. J. Geophys. Res.: Space Phys. 2014, vol. 119, no. 12, pp. 9790-9803. DOI: 10.1002/2014 ja020524.

Newell P.T., Liou K., Zhang Y., Sotirelis T., Paxton L.J., Mitchell E.J. OVATION Prime-2013: Extension of auroral precipitation model to higher disturbance levels. Space Weather. 2014, vol. 12, no. 6, pp. 368-379. DOI: 10.1002/2014sw001056.

Penskikh Yu.V. Applying the method of maximum contributions to the magnetogram inversion technique. Solar-Terr. Phys. 2020, vol. 6, no. 4, pp. 57-65. DOI: 10.12737/stp64202009.

Rigler E.J., Fiori R.A.D., Pulkkinen A.A., Wiltberger M., Balch C. Interpolating Geomagnetic Observations. Geomagnetically Induced Currents from the Sun to the Power Grid. Ed. by J.L. Gannon et al., Washington, D.C., USA, AGUWiley, 2019, pp. 15-41. DOI: 10.1002/9781119434412.ch2.

Ruohoniemi J.M., Baker K.B. Large-scale imaging of highlatitude convection with Super Dual Auroral Radar Network HF radar observations. J. Geophys. Res.: Space Phys. 1998, vol. 103, no. A9, pp. 20797-20811. DOI: 10.1029/98ja01288.

Russell C.T., McPherron R.L. The magnetotail and substorms. Space Sci. Rev. 1973, vol. 15, no. 2-3, pp. 205266. DOI: $10.1007 / b f 00169321$.

Shirapov D.S., Mishin V.M. Modeling of the global electrodynamic processes in the geomagnetosphere. Ulan-Ude, East Siberian State Technological University, 2009, 216 p. (In Russian).

Shukhtina M.A., Gordeev E.I., Sergeev V.A., Tsyganenko N.A., Clausen L.B.N., Milan S.E. Magnetotail magnetic flux monitoring based on simultaneous solar wind and magnetotail observations. J. Geophys. Res.: Space Phys. 2016, vol. 121, no. 9, pp. 8821-8839. DOI: 10.1002/2016ja022911.

Untiedt J., Baumjohann W. Studies of polar current systems using the IMS Scandinavian magnetometer array. Space Sci. Rev. 1993, vol. 63, no. 3-4, pp. 245-390. DOI: 10.1007/bf00750770.

Vorobjev V.G., Yagodkina O.I., Katkalov Y.V. Auroral precipitation model and its applications to ionospheric and magnetospheric studies. J. Atmos. Solar-Terr. Phys. 2013, vol. 102, pp. 157-171. DOI: 10.1016/j.jastp.2013.05.007.

Xiong C., Stolle C., Alken P., Rauberg J. Relationship between large-scale ionospheric field-aligned currents and electron/ion precipitations: DMSP observations. Earth, Planets and Space. 2020, vol. 72, no. 1, pp. 147. DOI: 10.1186/s40623020-01286-z.

URL: https://supermag.jhuapl.edu (accessed November 19, 2020).

URL: https://sourceforge.net/projects/ovation-prime/? source=typ_redirect (accessed November 19, 2020).

URL: http://apm.pgia.ru/webtool/frontend (accessed November 19, 2020).

URL: http://vt.superdarn.org/tiki-index.php?page=Radar +Overview (accessed November 19, 2020).

URL: https://omniweb.gsfc.nasa.gov/form/omni_min.html (accessed November 19, 2020).

How to cite this article

Penskikh Yu.V., Lunyushkin S.B., Kapustin V.E. Geomagnetic method for automatic diagnostics of auroral oval boundaries in two hemispheres of Earth. Solar-Terrestrial Physics. 2021. Vol. 7. Iss. 2. P. 57-69. DOI: 10.12737/stp-72202106. 